\begin{tabular}{|c|c|}
\hline Citation & $\begin{array}{l}\text { Ingrid Witters, Renee De Groot, Kristine Van Loo, Christine Willekens, } \\
\text { Audrey Coumans, Suzanne Frints, Jean-Pierre Frijns and Marcella } \\
\text { Baldewijns Tetralogy of Fallot with coronary artery to pulmonary artery fistula } \\
\text { Prenatal diagnosis, } 2014 \text {. }\end{array}$ \\
\hline Archived version & $\begin{array}{l}\text { Author manuscript: the content is identical to the content of the published } \\
\text { paper, but without the final typesetting by the publisher }\end{array}$ \\
\hline Published version & insert link to the published version of your paper DOI: $10.1002 / p d .4481$ \\
\hline Journal homepage & http://onlinelibrary.wiley.com/journal/10.1002/(ISSN)1097-0223. \\
\hline Author contact & $\begin{array}{l}\text { your email ingrid.witters@skynet.be } \\
\text { your phone number + } 32(0) 16 x x x x x x\end{array}$ \\
\hline IR & url in Lirias https://lirias.kuleuven.be/handle/123456789/459456 \\
\hline
\end{tabular}

(article begins on next page) 


\section{Tetralogy of Fallot with coronary artery to pulmonary artery fistula}

5 Running head: Tetralogy of Fallot -coronary to artery fistula

6

7 Ingrid Witters ${ }^{1,2,3} *$, Renee De Groot ${ }^{3}$, Kristine Van Loo $^{3}$, Christine Willekens ${ }^{3}$,

8 Audrey Coumans ${ }^{3}$, Suzanne Frints ${ }^{4}$, Jean-Pierre Frijns ${ }^{2}$ and Marcella Baldewijns ${ }^{5}$ 9

10 Word count: 665

11 Tables: 0

12 Figures: 2

$14{ }^{1}$ Department of Obstetrics and Gynecology, St-Jans Hospital, Genk, Belgium

$15{ }^{2}$ Center for Human Genetics, University of Leuven, Leuven, Belgium

$16{ }^{3}$ GROW School of Oncology and Developmental Biology, Maastricht University

17 Medical Centre+, Maastricht, the Netherlands

$18{ }^{4}$ Department of Clinical Genetics, Maastricht University Medical Center+, Maastricht,

19 The Netherlands

$20{ }^{5}$ Department of Pathology, Maastricht University Medical Center+, Maastricht, The

21 Netherlands

22

23 *Correspondence to: Ingrid Witters. E-mail: Ingrid.witters@skynet.be

25 The authors declare no conflict of interest 
1 WHAT'S ALREADY KNOWN ABOUT THIS TOPIC?

2 - Coronary artery fistulas (CAF) are rare anomalies with an incidence of $0.002 \%$ in 3 the population.

4

5 WHAT DOES THIS STUDY ADD?

6 - The association of tetralogy of Fallot, CAF and agenesis of the ductus arteriosus

$7 \quad$ has not been reported

8 - The discrepancy between the narrow pulmonary annulus with thickened

9 pulmonary valve and the large pulmonary trunk can be caused by extra blood 10 supply through the large fistula.

11 
1 We report a right coronary artery to pulmonary artery fistula as a rare congenital

2 malformation in a patient with tetralogy of Fallot and absent ductus arteriosus.

3 A healthy 33-year-old woman, gravida 3, para 1, was referred at 18+4 weeks with

4 suspicion of a fetal cardiac malformation. Her brother died neonatally from a

5 transposition of the great vessels.

6 Ultrasound examination in this pregnancy revealed a tetralogy of Fallot (TOF) with a

7 right-sided aorta and a narrow pulmonary artery annulus with only mild antegrade

8 flow, while the pulmonary trunk was well developed (Figure 1). No extracardiac

9 anomalies were seen. An amniocentesis showed a normal male CNV-profile.

10 The couple decided to terminate the pregnancy at $23+5$ weeks of gestation. The

11 autopsy showed a TOF with a right-sided aortic arch and agenesis of the ductus

12 arteriosus. Remarkable is the wide origo of the right coronary artery with a larger

13 artery branching from this right coronary artery and passing ventrally of the

14 pulmonary truncus and draining above the left anterior cusp into the lumen of the

15 pulmonary truncus (Figure 2). The left coronary artery was normal and no

16 extracardiac anomalies were found.

17 Congenital coronary artery fistulas (CAF) are characterized by a normal aortic origin

18 of the coronary artery involved but with a fistulous communication with the atria, the

19 ventricles or with the pulmonary artery, coronary sinus or the superior vena cava.

20 Coronary artery fistulas are rare anomalies encountered in $0.2 \%$ of angiographic

21 series. The incidence in the overall population is estimated $0.002 \%$. The right

22 coronary artery is most often involved in clinically detectable CAF. Fistulas most

23 frequently involve the right ventricle, closely followed, in terms of incidence, by

24 drainage into the right atrium or pulmonary artery. Left coronary fistulas are less

25 common, but usually drain into the right ventricle or right atrium. While coronary- 
1 cameral fistulas are abnormal connections between a coronary artery and a cardiac

2 chamber, the embryological basis of coronary artery to pulmonary artery fistulas can

3 be based on Hackensellner's involution persistence hypothesis ${ }^{1}$ proposing that there

4 are six anlages in the truncus of which two ,that are seen in the aortic sinuses, persist

5 and give rise to the coronary arteries while the others involute. Accordingly, the

6 normally involuted anlage from the pulmonary sinus persists and connects with the

7 anlage from the aortic sinus giving rise to these fistulas. ${ }^{2}$ Small congenital CAF can

8 be asymptomatic, larger more complicated CAFs can cause congestive heart failure,

9 myocardial ischemia due to a coronary steal effect, thrombosis, rupture and infective

10 endocarditis. Symptomatic CAF can be treated by selective ligature of the fistula tract

11 or transcatheter closure.

12 CAF can be found in isolation, or as in the present case in association with other

13 structural heart disease. The postnatal diagnosis can be suspected by

14 echocardiography, but cardiac catheterization is required to precisely evaluate the

15 vascular anatomy ${ }^{3}$. Isolated giant CAF has been diagnosed at 38 weeks of gestation,

16 and successfully treated in the neonatal period ${ }^{4}$. The prenatal diagnosis of ventriculo-

17 coronary artery fistula in the setting of PA-IVS has also been made previously ${ }^{5}$. In the

18 literature coronary-pulmonary artery fistulas (CPAF) have been reported in

19 association with TOF and pulmonary atresia in $10 \%$ and the majority of them have a

20 fistula originating from the left coronary artery with $>50 \%$ also having systemic-to-

21 pulmonary collateral arteries (MAPCAs) ${ }^{6}$.

22 Only one report described the prenatal diagnosis of a large fistula from the left

23 coronary artery to the left atrial appendage in TOF, with congestive cardiac failure

24 postnatally and death after surgical correction of TOF with ligation of the fistula at 3

25 months of age ${ }^{7}$. 
1 We did not find the association of TOF , CPAF and agenesis of the ductus arteriosus

2 as described in the present case. The fistula was only diagnosed at autopsy, but

3 prenatally we found a discrepancy between the narrow pulmonary annulus with a

4 thickened pulmonary valve with minimal flow at 22 weeks and the pulmonary trunk

5 that was adequately developed. This adequate pulmonary development can be caused

6 by extra blood supply through the large fistula.

7

8

9 Approvement of the ethical commission was not required for this manuscript.

REFERENCES

1. Heifetz SA, Robinowitz M, Mueller KH et al. Total anomalous origin of the coronary arteries from the pulmonary artery. Pediatr Cardiol 1986;7:11-8.

2. Vaidyanathan KR, Theodore SA, Sankar MN et al. Coronary artery to pulmonary artery fistula with dual origin--embryological, clinical and surgical significance. Eur J Cardiothorac Surg 2007;31:318-9.

3. Mangukia CV. Coronary artery fistula. Ann Thorac Surg 2012;93:2084-92.

4. Matsumoto Y, Hoashi T, Kagisaki K et al. Successful surgical treatment of a gigantic congenital coronary artery fistula immediately after birth. Interact Cardiovasc Thorac Surg 2012;15:520-2.

5. Chaoui R, Machlitt A, Tennstedt C. Prenatal diagnosis of ventriculo-coronary fistula in a late first-trimester fetus presenting with increased nuchal translucency. Ultrasound Obstet Gynecol 2000;15:160-2.

6. Garg P, Talwar S, Kothari SS et al. Management of pulmonary arterial supply dependent on a coronary arterial fistula in a patient with tetralogy of fallot 
with pulmonary atresia. World J Pediatr Congenit Heart Surg 2012;3:499-

2 503.

3 7. Khan MD, Sivasubramonian S, Simpson JM. Prenatal diagnosis of tetralogy

4 of Fallot associated with a fistula from the left coronary artery to the left

5 atrium. Cardiol Young 2003;13:194-6.

6

7 


\section{Legend to the figures}

2

3 Figure 1 Ultrasound with white pulmonary valve(arrow), well developed trunk

4 (dot)and right sided aorta.

5

6 Figure 2 Macroscopic view on the heart with aorta, pulmonary artery, 7 right coronary artery and the fistula. 